\title{
MEMÓRIAS DE UM CÃO: O HUMANITISMO DE MACHADO DE ASSIS TRANSPOSTO PARA A LINGUAGEM DRAMÁTICA
}

\section{EXPEDITO FERRAZ JÚNIOR}

Universidade Federal da Paraíba

João Pessoa, Paraíba, Brasil

Resumo: Este artigo consiste numa abordagem analítica do espetáculo Memórias de um cão (2015), do Coletivo de Teatro Alfenim, de João Pessoa, Paraíba.

Descrevemos as aproximações que essa obra mantém com a ficção de Machado de Assis, destacando-lhe aspectos relativos à adaptação (aqui tratada como transposição), para a linguagem dramática, de elementos estruturais dos romances Quincas Borba (1891) e Memórias póstumas de Brás Cubas (1881). Tomando como ponto de partida o conceito de "tradução intersemiótica", de Roman Jakobson,e seus desdobramentos, procuramos descrever os principais procedimentos e soluções dramatúrgicas adotadas para estabelecer correspondências com certos efeitos de sentido pertinentes à narrativa machadiana nesse novo contexto, em que o diálogo intertextual se define também como um processo de transposição midiática.

Palavras-chave: Machado de Assis; romance; teatro; adaptação; semiótica

\section{MEMÓRIAS DE UM CÃO: THE HUMANITISM TRANSLATED INTO DRAMATIC LANGUAGE}

Abstract: This paper is an analytical approach to the piece of theater, Memórias de um cão (2015) performed by Coletivo de Teatro Alfenim, from João Pessoa, Paraíba, Brazil. The article describes the approaches that this work takes in relation to the fictional narrative produced by Brazilian writer Machado de Assis, underlining the aspects regarding the adaptation (herein referred to as transposition) of structural elements in the novels Philosopher or Dog? (1891) and Posthumous Memoirs of Brás Cubas, or Epitaph of a Small Winner (1881) to dramatic language. Considering Roman Jakobson's concept of intersemiotic translation and its developments, we intend to describe the main procedures and dramaturgical solutions adopted to establish a correspondence between certain effects of meaning pertinent to Machadian narrative in this new context, where the intertextual dialogue also defines itself as a procedure for transposingmedia.

Keywords: Machadode Assis; novel; drama; adaptation; semiotics 


\section{Introdução}

um ensaio pioneiro sobre o tema da tradução, ${ }^{1}$ Roman Jakobson
propõe a seguinte distinção entre modalidades do que ele chamou
de tradução intralingual, interlingual e intersemiótica:

A tradução intralingual ou reformulação (rewording) consiste na interpretação dos signos verbais por meio de outros signos da mesma língua.

A tradução interlingual ou tradução propriamente dita consiste na interpretação dos signos verbais por meio de alguma outra língua.

A tradução intersemiótica ou transmutação consiste na interpretação dos signos verbais por meio de sistemas de signos não verbais. ${ }^{2}$

Ao evocar exemplos dessa última categoria, Jakobson refere-se à transposição"da arte verbal para a música, a dança, o cinema ou a pintura". ${ }^{3}$ A divisão se mostra, até certo ponto, eficaz, mas percebem-se, de imediato, algumas lacunas no que tange à aplicação do conceito. Decerto porque tais definições não eram o foco principal desse ensaio, nem era o objetivo particular do autor esmiuçar as inúmeras variáveis envolvidas nessa aplicação, fato é que a polarização entre sistemas de signos "verbais" e "não verbais", de que ele parte, aqui se mostra em certa medida válida, mas não suficiente. As três categorias propostas não contemplariam, por exemplo, uma virtual tradução entre dois sistemas não verbais (no que seria igualmente uma relação intersemiótica), nem preveem as muitas relações que delas se desdobram quando consideramos os sistemas semióticos complexos - aqueles que reúnem linguagens diversas, inclusive a palavra, como é o caso do teatro, da televisão e do cinema.

Mais recentemente, o conceito de tradução intersemiótica foi retomado e ampliado por Julio Plaza, ${ }^{4}$ que o explorou num estudo minucioso, empregando fundamentos da Teoria geral dos signos, de Charles Sanders Peirce, - especificamente sua segunda tricotomia dos signos - para postular uma tipologia das traduções dessa espécie, as quais se dividiriam, segundo ele, em icônicas, indiciais e simbólicas. ${ }^{5}$ De acordo com Plaza, a tradução

\footnotetext{
${ }^{1}$ JAKOBSON, Aspectos linguísticos da tradução, p. 64-65.

${ }^{2}$ Ibidem, grifos no original.

${ }^{3}$ Idem, p. 74.

${ }^{4}$ PLAZA, Tradução intersemiótica.

${ }^{5}$ Idem, p. 89-94.
} 
icônica é aquela que "se pauta pelo princípio da similaridade de estruturas" entre o original e a tradução, de modo a "produzir significados sob a forma de qualidades e de aparências". A tradução indicial se define"pelo contato entre original e tradução. Suas estruturas são transitivas, há continuidade entre original e tradução. O objeto imediato do original é apropriado e transladado para um outro meio". Já a tradução simbólica "opera pela contiguidade instituída, o que é feito através de metáforas, símbolos ou outros signos de caráter convencional" ${ }^{6}$

A partir desses conceitos, já se pode presumir que a adaptação de uma narrativa de ficção para o teatro, pela própria natureza complexa das duas linguagens envolvidas, se utilizará de todas as três formas de tradução acima definidas. Basicamente, trata-se de transformar um texto verbal num produto semiótico complexo, formado por um novo texto a que potencialmente se associarão: imagens (performance dos atores, cenário, figurino, iluminação), som (música, texto falado, sonoplastia) e todas as possíveis relações entre essas duas espécies de signos. Por outro lado, devese considerar que uma adaptação desse gênero nunca traduz uma obra em sua totalidade: a obra tradutora elege determinados elementos significantes com potencial para produzir os efeitos estéticos desejados, ao serem transpostos para a linguagem cênica.

Ora, sendo o nosso entendimento o de que, na leitura de um mesmo texto, quer seja ele verbal ou não verbal, surgirão aspectos simbólicos, indexicais e icônicos a serem destacados, faremos a seguir um emprego substancialmente diverso do que propõe Júlio Plaza, definindo a tríade das traduções intersemióticas com base não nas características do novo representâmen produzido, mas na natureza dos elementos traduzidos, desde a forma que eles apresentam no texto de origem. Desse modo, ao invés de analisarmos, por exemplo, aquilo que Plaza chamou de tradução simbólica, definindo-a como tradução através de "signos de caráter convencional", buscaremos distinguir e descrever uma tradução de elementos predominantemente simbólicos, indexicais ou icônicos contidos na obra traduzida, qualquer que seja a natureza semiótica do novo representâmen produzido em cada caso.

Feitas essas observações, convém ainda explicarmos o que estamos entendendo por elementos predominantemente icônicos, indexicais e simbólicos numa obra literária de ficção. Se, para Peirce, ${ }^{7}$ o signo simbólico é

${ }^{6}$ Idem, p. 92-93.

${ }^{7}$ PEIRCE, Semiótica e filosofia. 
uma forma de representação que se caracteriza pela existência de uma norma ou hábito interpretativo segundo os quais estabelecemos a relação entre o signo e o seu objeto, ${ }^{8}$ tudo o que, num processo de leitura de uma obra, nos remete a regras culturalmente adquiridas perfaz o núcleo das representações simbólicas. Assim, além das regras linguísticas que orientam a leitura, os próprios traços do gênero literário (no caso, a narrativa romanesca) e do estilo de época a que pertence tal obra, e até mesmo do estilo individual consagrado como marcas de um escritor, envolvem considerações de símbolos. Quando nos referimos, portanto, a certo conceito de literatura machadiana, estamos nomeando um conjunto de normas ou hábitos que definem tal conceito - uma representação simbólica. Preservar esses caracteres numa adaptação, em linguagem teatral, é traduzir a dimensão simbólica dessa experiência.

Analogamente, consideremos a definição peirciana para o índice: tratase de um signo cuja associação com o seu objeto se deve a uma ligação factual entre ambos, de modo que a existência do primeiro seja decorrência da existência do último. ${ }^{9}$ Os índices consistiriam assim de marcas ou vestígios da ocorrência do objeto. Este, por sua vez, possui a natureza de um fenômeno singular, circunstancialmente definido, e não de uma ideia geral, como é o caso dos objetos dos símbolos. Os exemplos clássicos para uma tal forma de representação recaem em relações como as que se dão entre fumaça (índice) e fogo (objeto), ou entre a pegada de um animal (índice) e sua presença (objeto) num dado lugar. Estes são os índices genuínos - cuja ocorrência num texto literário impresso é praticamente inexistente ou inexpressiva. Entretanto, Peirce considera ainda a existência de índices degenerados, ou subindicadores, que são aqueles que, mesmo não possuindo uma ligação física, de fato, com o objeto, fazem referência diretamente a fenômenos de natureza singular, ou ocorrências. Nomes próprios, datas, certos pronomes etc. atuam no código verbal com essa função: indicar algo circunstancialmente definido. Nesse sentido, as mais diversas formas de referência num texto, quer sejam referências endofóricas ou exofóricas, são resultado da presença de índices. Ora, tudo o que numa obra literária tenha a função de indicar lugares reais, acontecimentos históricos, ou de evocar outras obras pode ser enquadrado no conjunto das representações indexicais.

${ }^{8}$ Idem, p. 126-130.

${ }^{9}$ Idem, p. 120-125. 
E, finalmente, a semiótica peirciana conceitua uma terceira classe de signos, cuja relação com o objeto representado se dá pela semelhança entre ambos: estes são os signos icônicos. ${ }^{10}$ Assim como ocorre com os índices, os ícones também apresentam níveis de degeneração. Daí que a teoria os divida em três subcategorias: as imagens, os diagramas e as metáforas. Neste contexto específico, importa perceber que há níveis diferentes de semelhança entre o signo e o objeto, na iconicidade. Desse modo, haverá passagens de um romance em que ressaltam os aspectos qualitativos dos objetos descritos, e as imagens que projetamos desses objetos no ato de leitura têm a natureza de um ícone. Traduzir ícones presentes em textos narrativos corresponderia, portanto, a utilizar recursos capazes de materializar a experiência sensorial do leitor na apreensão dessas representações. Assim, praticamente todos os recursos cenográficos, musicais e toda a performance empregados na adaptação de uma narrativa para a linguagem dramática consistem na criação de ícones.

Nos parágrafos que seguem, buscaremos analisar algumas das implicações do processo de tradução assim considerado. No caso em apreço, trata-se de duas obras de Machado de Assis, originalmente veiculadas em livro, ou seja, transmitidas ao público através do código verbal impresso, relidas e recriadas no ambiente midiático do teatro, em que se associam ao texto uma variedade de recursos não verbais e a própria relação imediata, em presença, com um público espectador.

\section{Leitura de uma releitura: as Memórias de um cão}

Teatro e narrativa miram-se todo o tempo na obra de Machado de Assis. Se a dramaturgia, propriamente dita, nunca alcançou, em sua produção, a genialidade dos melhores contos e romances, não é raro encontrarmos, nesses últimos, alusões a clássicos do gênero dramático com os quais dialogam seus enredos e nos quais se espelha, por vezes, o comportamento de suas personagens. Assim, vemos Otelo citado em Dom Casmurro (1900); Hamlet, no conto "A cartomante" (1884); Macbeth, em Memórias póstumas de Brás Cubas (1881) - para ficarmos apenas com essas três referências shakespearianas. Na trama de intertextos que dá forma ao estilo machadiano, obras-primas desse gênero são referidas e revisitadas com

\footnotetext{
${ }^{10}$ Para os propósitos deste trabalho, evitamos desenvolver a distinção teórica entre ícone ideal e signos icônicos. Cf. PEIRCE, cit. p. 116.
} 
frequência, muitas vezes em tom de paródia. E não menos frequentes são as passagens de suas histórias em que o teatro se materializa como espaço físico representado no cenário urbano, investindo-se de um significado social marcante no modo de vida oitocentista e cortesão ali retratado.

Uma vez provocada por essas referências, não estranha que a imaginação do leitor se anime a projetar o movimento inverso: o de transpor elementos do romance machadiano para o contexto da linguagem dramática. É essa a aventura em que se (e nos) lança o Coletivo de Teatro Alfenim, de João Pessoa, Paraíba, em Memórias de um cão, que estreou em maio de 2015. O espetáculo integra um projeto chamado "Figurações brasileiras", e nasce de um cuidadoso trabalho de pesquisa iniciado em 2014, com um seminário intitulado "A atualidade de Machado de Assis".

Pois é justamente disso que se trata: de atualidade, porque esta é a impressão que nos causa a experiência de revisitarmos o pensamento de Machado hoje e de refletir, com ele, acerca das contradições que definem a nossa formação social, numa mirada sempre reveladora e inquietante. Tanto mais se essa releitura nos permite observar ainda outra forma de atualização: a da transposição de mídias - vale dizer: da tradução (como se definiu anteriormente) para a linguagem cênica do mais agudo tradutor de nossas mazelas sociais. É sobre esse processo de transposição e seus efeitos que vamos nos deter brevemente nos parágrafos que seguem. Para tanto é que revisitamos, na Introdução deste trabalho, o conceito teórico de tradução intersemiótica, que nos serve de base, delimitando em seguida o sentido em que o aplicaremos.

$\mathrm{O}$ argumento central dessas Memórias segue de perto, principalmente, o enredo do romance Quincas Borba, publicado em 1891. É, portanto, o relato da ruína material e psicológica do provinciano Rubião, subitamente alçado à condição de novo rico, graças à herança que lhe deixara o amigo Quincas, mas destruído pelas relações de poder em que se envolve desde que decide viver na Corte. Também aqui, como no romance, Quincas Borba são dois: o finado benfeitor de Rubião e um cachorro, batizado com o nome do primeiro dono e deixado sob os cuidados do protagonista (esta é a condição para que lhe seja destinada a herança). Chegamos assim, machadianamente, à primeira e decisiva intervenção criativa do Coletivo Alfenim sobre o texto que lhe serve de base, a saber: a inserção de um ponto de vista intradiegético - pois é pelo ângulo desse cachorro que assistimos aos infortúnios de Rubião -, perspectiva que serve também como uma moldura narrativa para toda a ação dramática. 


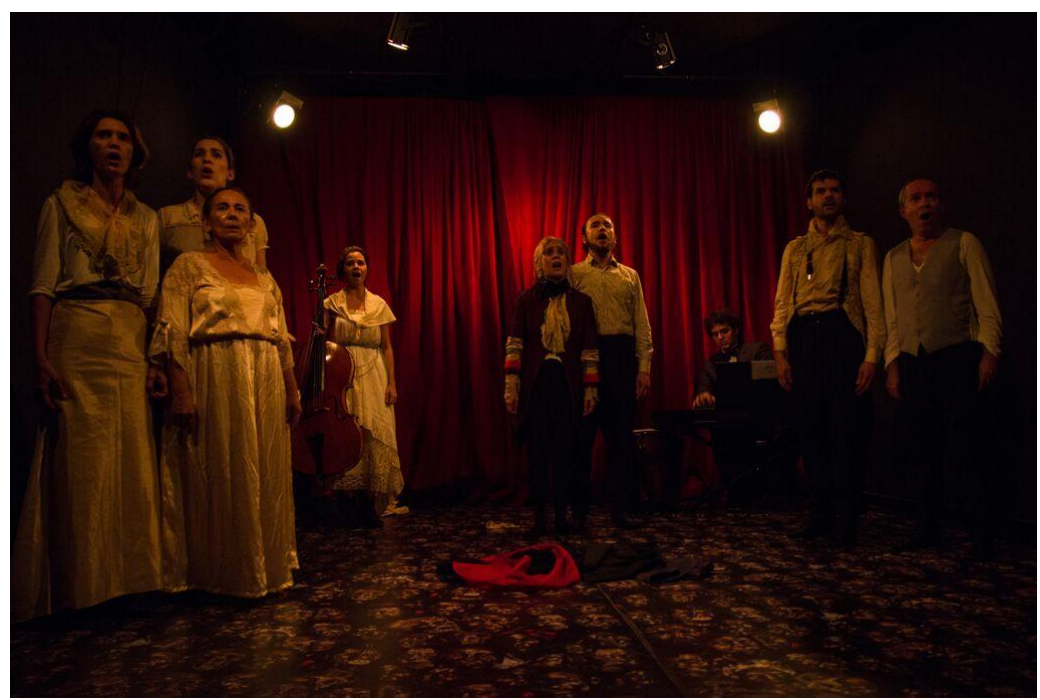

Fotografia 10 elenco de Memórias de um cão: à esquerda, Verônica Sousa, Lara Torrezan e Zezita Matos; à direita, Adriano Cabral e Ricardo Canella; ao centro, Paula Coelho e Vítor Blam; ao fundo, os músicos e atores Mayra Ferreira e Nuriey Castro. ${ }^{11}$

Isso, que parece um mero detalhe, é na verdade a senha para que se instaure e se justifique, no espaço concreto e no tempo presente do palco, certa atmosfera de irrealidade. Diferentemente do que ocorre na história de Rubião, em que o ilógico, visto a distância pelo leitor, vai-se insinuando gradativamente, à medida que se manifesta a loucura do protagonista, aqui esse efeito é compartilhado com o público desde o título do espetáculo. Assim, o deslocamento do cão Quincas Borba para a condição de narradorpersonagem traz ao texto encenado um ingrediente nonsense que, em certo sentido, corresponderia, no acordo ficcional com o espectador, à natureza daquele narrador das Memórias póstumas de Brás Cubas (1881) - outro romance do mesmo autor, com que também dialoga, livremente, essa recriação. Tanto é assim que a narrativa do cão, também chamada de memórias, se inicia justamente numa alusão ao "capítulo primeiro" de Brás Cubas: "Algum tempo hesitei se devia abrir estas memórias pelo início ou pelo fim...", revelando-se, também, ao final, como uma narrativa póstuma, no sentido peculiar que lhe deu o narrador machadiano.

${ }^{11}$ Todas as fotografias reproduzidas neste artigo pertencem ao acervo do Coletivo de Teatro Alfenim. 


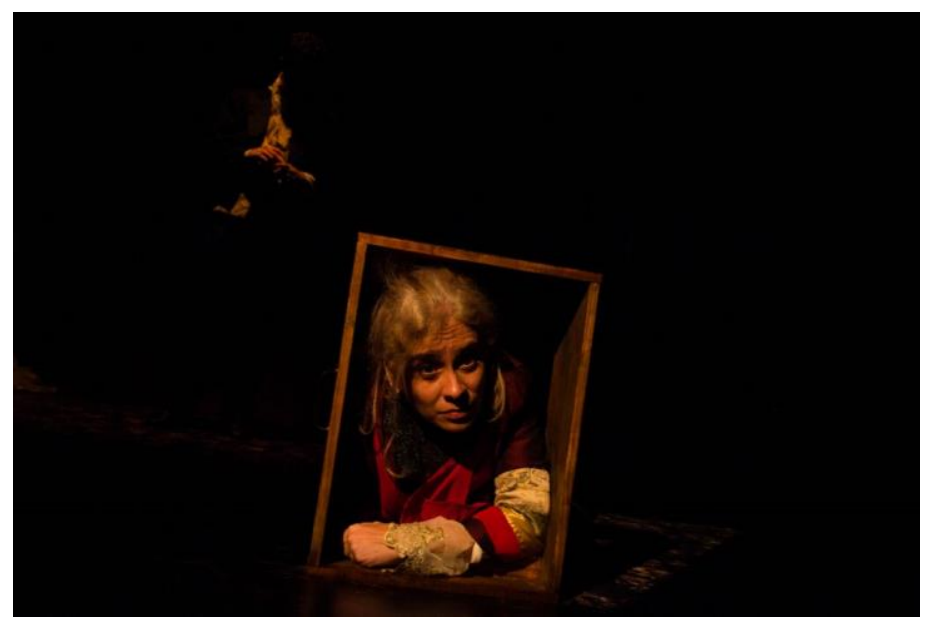

Fotografia 2 A atriz Paula Coelho interpreta o cão Quincas Borba

Muito embora não seja engraçada em sua essência (é, antes, triste), a figura desse narrador canino é, como dissemos, um link para o inverossímil, para a liberdade de fabulação - com o que contribui decisivamente para a tonalidade tragicômica de que a obra se recobrirá. E não há nisso nada de tão estranho, afinal, ao espírito das Memórias póstumas, que (lembremos) foram escritas "com a pena da galhofa e a tinta da melancolia". Por outro lado, o cão suscita certa empatia necessária ao faz de conta lúdico que a montagem teatral pressupõe, mais do que as narrativas de ficção realistas. Nem deixemos de anotar, ainda, que o atributo do cinismo, tantas vezes associado a narradores machadianos, traz em sua etimologia alguma relação com a palavra cão (aqui representada na forma literal e concreta). Todavia, a principal função desse exótico narrador parece ser a de enfatizar a crítica de costumes através de um olhar apartado da vida social, porque situado à margem das relações empenhadas no favor, no interesse e nas paixões humanas. Um olhar muito semelhante, nesse aspecto, ao do "defunto autor" machadiano. Mas, se no caso de Brás Cubas era a condição fantástica da narrativa post mortem que garantia o descompromisso com os contratos sociais, aqui é a condição diferenciada do animal, entre humanos, que nos permite a fruição dessa outridade crítica.

O espetáculo do grupo Alfenim (assim como os dois romances que o inspiram) quer ilustrar a conhecida sátira de Machado de Assis ao cientificismo de seu tempo: a pretensa doutrina filosófica que ele batizou de Humanitismo e atribuiu, no plano ficcional, ao excêntrico Quincas Borba (primeiro dono e homônimo do cão, de quem já falamos). No palco, as lições 
do filósofo maluco sobre Humanitas (o princípio universal) e sua única lei - a autopreservação (que justificaria inclusive, ou sobretudo, a ação destruidora dos mais fortes sobre os mais frágeis) - são didaticamente expostas ao público em quadros cômicos que se intercalam ao enredo mais grave, aparentemente com função secundária. A ação vai sendo pontuada, entretanto, pelos postulados irônicos da teoria, que o movimento das personagens acaba por confirmar. E chega assim ao clímax dramático, na bela representação do delírio de Rubião, atormentado por sonhos de grandeza (evidentemente frustrados) e pela impiedosa trama de sedução e bajulação em que se viu enredado.

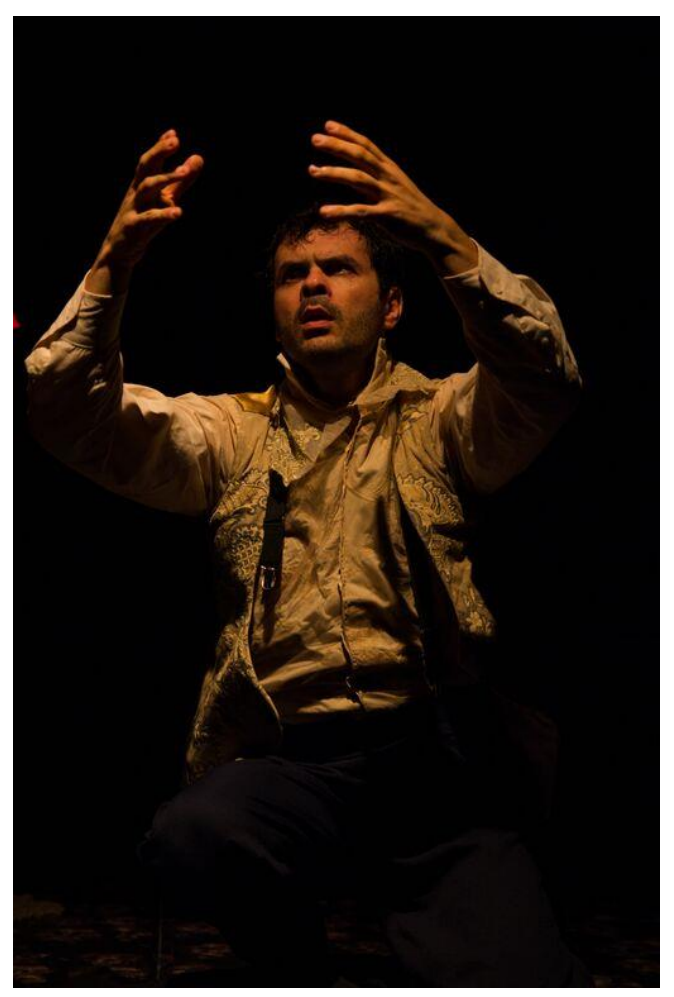

Fotografia 3 Rubião (Adriano Cabral) cinge sua imaginária coroa de imperador

Em meio a tudo isso, há certos artifícios cenográficos que materializam - vale dizer: que traduzem iconicamente - e dão relevo a um aspecto das obras recriadas que está apenas insinuado nas sutilezas da ironia machadiana: trata-se da dimensão ideológica de práticas que se ritualizam, veladas ou atenuadas, em nosso contexto social, mas que, contraditoriamente, escandalizam o público (ou o leitor) quando se expõem, assumidas e justificadas, no discurso cínico da extravagante doutrina. 
Considere-se, por exemplo, a cena com que se inicia a peça: é a execução solene de um escravo rebelado, saudada pela multidão (fantoches preenchem o espaço cênico, manuseados pelo elenco) com aplausos e clamores de justiça. Toda essa cena, assim como a música e o figurino da peça cumprem certa função indexical, ou seja, atuam como índices da realidade brasileira na época retratada.

Noutra passagem, entretanto, essa referência se atualiza, pois espelhos são usados em cena, estrategicamente voltados para o público presente. Uma vez refletida, a plateia se vê como que transformada em personagem, transportada para o centro do palco - o espaço que definiria, por regra, os limites entre o real e o ficcional, na linguagem do teatro. Há, por fim, o emprego de máscaras que se multiplicam num coro de rostos idênticos, emprestando às palavras de Quincas Borba a força de um canto coletivo. Todos esses recursos têm a função de nos advertir que o riso ali suscitado é essencialmente desvelador, pois o retrato grotesco dessa sociedade de favores, que ali contemplamos, é, na verdade, um espelho. E a fábula do Humanitismo fala de nós.

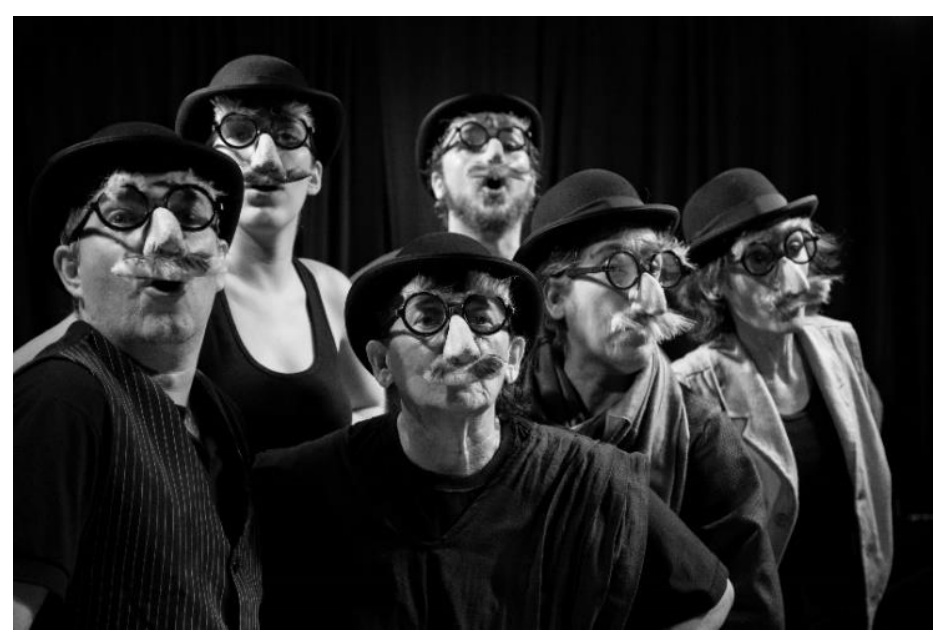

Fotografia 4 - Um coro de mascarados representa o filósofo Quincas Borba.

Além desses aspectos, especificamente relacionados à linguagem teatral, também se deve observar que essas Memórias parecem resultar de uma leitura extremamente cuidadosa dos textos em que se apoiam. Mas não falo apenas de uma leitura perspicaz, atenta à fruição estética das obras (esta, obviamente necessária). Penso num tipo especial de leitura, seletiva, voltada para a apreensão de alguns elementos-chave que possam render intensidade e significação no novo contexto midiático a que se destinam - uma leitura 
típica do olhar tradutor. Isto se evidencia em certas correspondências muito particulares, que pontuam esse trabalho de transposição do Coletivo Alfenim. Uma dessas equivalências, que pode ilustrar todo o procedimento, é a que envolve o tema da loucura e sua representação.

Num ensaio bastante questionador sobre Quincas Borba, a professora Leda Tenório da Motta ${ }^{12}$ chama atenção para um ponto, no romance, em que a fronteira entre razão e loucura parece ter sido cruzada em definitivo. É o instante em que o narrador, como que assimilando a fantasia subjetiva de Rubião, expressa o que a autora chama de uma "dissociação psicótica em azul". Cito o trecho comentado (o grifo é meu): "Rubião tinha nos pés um par de chinelas de damasco, bordadas a ouro, na cabeça, um gorro com borla de seda preta. Na boca, um riso azul-claro". Ora, é de notar que, exatamente no recurso cenográfico da iluminação - no jogo cromático das luzes intermitentes (não em azul, mas em verde) - consiste toda a plasticidade da cena culminante nas Memórias de um cão: a do delírio do protagonista. Mais do que isso, pode-se afirmar que o efeito óptico (cromático), neste caso, se impõe sensorialmente ao público, que não apenas assiste, mas experimenta a visão alucinada do protagonista - num trabalho experto e criativo de tradução icônica.

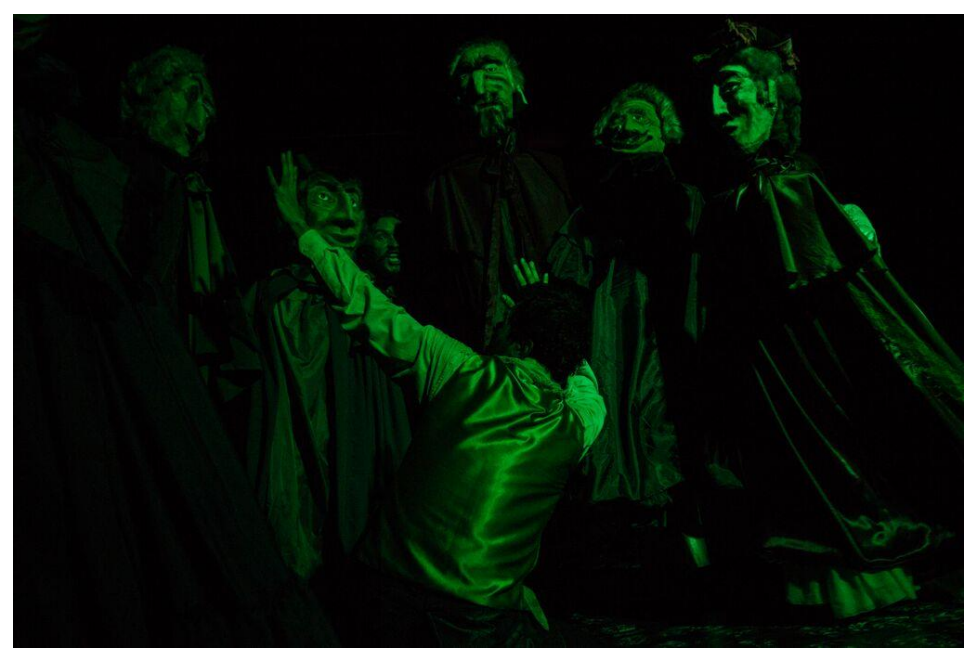

Fotografia 5 Rubião (Adriano Cabral) enlouquece.

${ }^{12}$ MOTA, Um riso azul-claro: a loucura machadiana com e sem o socorro sociológico, p. 125-146. 
Em cada um desses aspectos percebe-se o cuidado com o detalhe no arranjo dos elementos reunidos no palco em mais de uma hora e meia de espetáculo: da iluminação ao cenário, do figurino à música (executada/cantada ao vivo), do texto à interpretação. Esta última se equilibra todo o tempo em contrapontos de expressões: ora intimistas e contidas, como as de Lara Torrezan (Sofia), Zezita Matos (Dona Plácida), Verônica Sousa (Quincas Borba, o filósofo) e Paula Coelho (o cão); ora expansivas e enérgicas, como as de Adriano Cabral (Rubião), Vítor Blam (Palha) e Ricardo Canella (Camacho). O resultado é uma bela homenagem ao criador do Humanitismo. Pois, se Machado de Assis inscreve o universo do teatro em suas narrativas, apropriando-se dessa tradição com liberdade, pela via do "rebaixamento" e das alusões paródicas, o espetáculo do Coletivo Alfenim quer retribuir esse gesto de assimilação, brincando seriamente de transportar para o palco a crítica social e a densidade psicológica que marcam a literatura do nosso maior escritor.

\section{Considerações finais}

A adaptação para o teatro de uma narrativa literária envolve, como pudemos assinalar, níveis diversos de uma operação tradutória. No exemplo aqui analisado, esses níveis podem ser considerados a partir da ênfase nos aspectos simbólicos, indexicais ou icônicos destacados dos romances tomados como ponto de partida. Podemos afirmar, por exemplo, que o conjunto dos traços de estilo de Machado de Assis, conhecidos e sistematizados pelos estudos literários, constituem um signo complexo que o leitor apreende, e que, por ter a natureza de um aprendizado cultural, consolidado e reconhecido pelo leitor como uma espécie de norma para a leitura desse autor, pode ser considerado como uma representação simbólica. Assim, quando a adaptação cênica enfatiza esse conjunto de traços, ocorre nessa releitura uma tradução intersemiótica de caráter simbólico. Por outro lado, quando os aspectos privilegiados pela recriação consistem nas referências, contidas nos romances, a lugares e fatos reais - ou seja, quando o registro documental da realidade brasileira, representada pelo escritor, ocupa o primeiro plano da adaptação -, dá-se uma ênfase à dimensão indexical da leitura. E, finalmente, quando as imagens machadianas encontram correspondência nos recursos cênicos empregados, ressalta o 
caráter icônico da tradução. O que procuramos demonstrar, no comentário acerca da obra dramática Memórias de um cão, foi a complexidade desses diferentes níveis de leitura envolvidos na adaptação dos romances machadianos, bem como a eficácia com que se realizou esse tríplice processo de transposição na adaptação comentada.

\section{Referências}

ASSIS, Machado de. Memórias póstumas de Brás Cubas. São Paulo: Abril Cultural, 1978.

. Quincas Borba. 8. ed. São Paulo: Ática, 1999.

COLETIVO ALFENIM. http://coletivoalfenim.com.br. Acesso em: 7 fev. 2016.

JAKOBSON, Roman. Aspectos linguísticos da tradução. In: Linguística e comunicação. 15. ed. São Paulo: Cultrix, 1995, p. 66-72.

MOTA, Leda Tenório. Um riso azul-claro: a loucura machadiana com e sem o socorro sociológico. In: Sobre a crítica literária brasileira no último meio século. São Paulo: Imago, 2002, p. 125-146.

PEIRCE, C. S. Semiótica e filosofia. Tradução e organização de Octanny Silveira da Mota e Leonidas Hegenberg. São Paulo: Cultrix; Edusp, 1975.

PLAZA, Julio. Tradução intersemiótica. 2. ed. São Paulo: Perspectiva, 2013.

EXPEDITO FERRAZ JÚNIOR é professor de Teoria da Literatura do Departamento de Letras Clássicas e Vernáculas da Universidade Federal da Paraîba, e do Programa de PósGraduação em Letras da mesma instituição, atuando na linha de Estudos Semióticos. É autor de Semiótica aplicada à linguagem literária (UFPB/UaB, 2012) e de Poheresia (Ed. A União, 2014), e editor da Revista Graphos do PPGL/UFPB. Publicou artigos científicos em revistas nacionais, a exemplo de Signos (Unisc), Estudos Semióticos (USP) e CASA Cadernos de Semiótica Aplicada (Unesp); e capítulos de livros, a exemplo de "Os sonetos que não acabam: considerações sobre a poesia de Augusto dos Anjos", "Leitura de intertextos: um conto de Mia Couto" (Mídia Gráfica e Editora, 2015) e "Pressupostos para uma pesquisa em semiótica peirciana aplicada aos estudos literários" (UFPB, 2012). Email: expeditoferrazj@@gmail.com. 